\title{
CORRIGENDUM
}

\section{Atomic clock transitions in silicon-based spin qubits}

Gary Wolfowicz, Alexei M. Tyryshkin, Richard E. George, Helge Riemann, Nikolai V. Abrosimov, Peter Becker, Hans-Joachim Pohl, Mike L. W. Thewalt, Stephen A. Lyon and John J. L. Morton

Nature Nanotechnology 8, 561-564 (2013); published online 23 June 2013; corrected after print 26 September 2013.

In the version of this Letter originally published, ref. 21 should have read: Morley, G. W. et al. Quantum control of hybrid nuclearelectronic qubits. Nature Mater. 12, 103-107 (2013). This error has been corrected in the HTML and PDF versions of the Letter. 